\title{
ENCAPSULATION OF BARBERRY FRUIT EXTRACTS BY SPRAY DRYING AND LIPOSOME ENTRAPMENT
}

\author{
S. Berenji Ardestani ${ }^{a}$, M.A. SAHARi ${ }^{b *}$ and M. BARZEGAR ${ }^{b}$ \\ ${ }^{a}$ Former Ph.D. Student, Tarbiat Modares University and Assistant Professor of Research School of Radiation \\ Applications, Nuclear Science and Technology Research Institute, AEOI, Tehran. Iran \\ ${ }^{b}$ Department of Food Science and Technology, Faculty of Agriculture, Tarbiat Modares University, Tehran. Iran
}

(Received: 13 June 2019; accepted: 11 January 2020)

\begin{abstract}
Barberry is a native Iranian plant including species Berberis integerrima and B. vulgaris. Barberry fruit is used for preparing sauces, jellies, carbonated drinks, candies, food colour powders, jams, marmalades, chocolates, juices, and nectars. They are used as a natural food colorant rich in anthocyanins instead of harmful artificial ones. They contain polyphenols and antioxidants that reduce damage from free radicals and prevent chronic diseases and cancers. Barberry fruit extracts were encapsulated in maltodextrin by spray drying and Liposome Entrapment. The sizes of spray dried particles were reported $1-20 \mu \mathrm{m}$ by SEM. Dimensions of empty and extract loaded liposomes $(B$. vulgaris and $B$. integerrima) were 18-28, 37-51, and 51-77 nm, respectively, by FE-SEM. The moist diameter of liposomes measured by dynamic light scattering (DLS) method at day 0 and after 6 months at $-18{ }^{\circ} \mathrm{C}$ were as follows; empty liposomes: 163.9 \pm 2.23 and $378.90 \pm 4.98$, liposomes loaded with extracts: $135.2 \pm 2.04$ and $160.90 \pm 2.19$ (B. vulgaris) and $113.4 \pm 1.83$ and $144.20 \pm 2.01 \mathrm{~nm}$ (B. integerrima). Evaluation of thermal-oxidative decomposition from differential scanning calorimetry (DSC) results at 0-45-90 days showed that the antioxidant activity and the onset temperature of the encapsulated extract was higher than the control. The extracts encapsulated in liposomes, especially $B$. integerrima extract, had better antioxidant properties.
\end{abstract}

Keywords: encapsulation, barberry, spray drying, maltodextrin, liposome

Preserving functional compounds of food and fruits is a must. Loading different compounds in a contiguous capsule is known as encapsulation. The benefits of encapsulation include reducing the rate of environmental conversion, facilitating transport, especially in liquid and gases, and protecting desirable and covering undesirable properties during storage (MORTAZAVI et al., 2008). Two important encapsulating processes are spray drying and liposome entrapment. Spray drying encapsulation is a flexible, easy to use, and economical method (it costs 30-50 times less than freeze drying) to convert solutions into high quality powders. Maltodextrin as a carbohydrate is a proper wall material, which can protect oils from oxidisation, but its emulsifying capacity, emulsion stabilising ability, and core preserving properties are weak. Liposome is a special spherical structure composed of many phospholipid units. These units are located radially adjacent to each other. The hydrophilic heads of the molecules are located outside, and the hydrophobic tails point inwards. Therefore, a stable globule with a hydrophilic surface is formed in an aqueous solution. The size of capsules is in the range of micron to nanometre (SAENZ et al., 2009; FANG \& BHANDARI, 2010).

\footnotetext{
* To whom correspondence should be addressed.

Phone: +98 21 48292328; fax: +98 21 48292200; e-mail: sahari@modares.ac.ir
} 


\section{Materials and methods}

\subsection{Solvents, reagents, and standards}

Maltodextrin (Dextrose equivalent (DE) 16.5-19.5) (Sigma, USA), food grade phosphatidylcholine (PC) (Behpak company, Iran), cholesterol (C) (Sigma, USA), phosphate buffer saline (PBS) $\mathrm{pH}=7.4$, chloroform and methanol (Merck, Germany) were purchased.

\subsection{Preparation of extracts and encapsulation of the powder of extracts}

The extracts were prepared using dried (for more precise and easier extraction), ground berries of two varieties of barberry fruit (Berberis vulgaris and Berberis integerrima) by the method of MOTALLEB and co-workers (2005) in water as solvent (for safety and cost saving reasons), darkness, $\mathrm{pH}=3$, at $25{ }^{\circ} \mathrm{C}$ (BERENJI ARDESTANI et al., 2016). Encapsulation of the extract powders in maltodexterin as wall material were prepared by spray drying under the following conditions; inlet air temperature $150{ }^{\circ} \mathrm{C}$, outlet air temperature $70{ }^{\circ} \mathrm{C}$, air flow rate

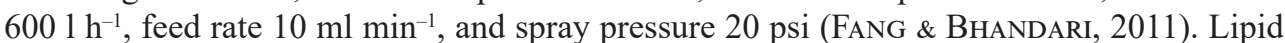
components of liposomes consisted of $10 \mathrm{mg} \mathrm{ml}^{-1}$ phosphatidylcholine (PC) and $2 \mathrm{mg} \mathrm{ml}^{-1}$ cholesterol (C). Liposomes were prepared by mechanical shaking or thin layer method. Researchers believe that ultrasonic bath (Elma, D78224, Germany) is better than probe sonication, because it does not contaminate liposomes with transferred metals from the probe (ROBERTS \& GORDON, 2003; GorTZI et al., 2007; FAN et al., 2007). The extract of barberry fruit (1.5 $\mathrm{mg} \mathrm{ml}^{-1}$ ) in liposomes can be used as an antioxidant agent (MoHAN, 2003).

\subsection{Scanning electron microscopy (SEM)}

The size distribution of spray dried microcapsules and liposome structures were studied by SEM (XL30, Philips, Netherlands) and Field Emission Scanning Electron Microscopy (FESEM) (Hitachi S4160, Japan), respectively (GoRTZI et al., 2007).

\subsection{Evaluating liposome size}

The size of particles was measured by Dynamic Light Scattering (DLS) in a Zeta-sizer, Nano series, Nano- zs Malvern (U.K.) at $25^{\circ} \mathrm{C}$ (FAN et al., 2007).

\subsection{Differential scanning calorimetry (DSC)}

This method estimates the antioxidant ability of encapsulated extracts. This test was done at 0, 45, and 90 days after encapsulating the extracts by means of Mettler Toledo, DSC 822 (Swiss) using GoRTZI and co-workers' (2007) method.

\subsection{Statistical analysis}

All experiments were performed in triplicate. The results were analysed using completely randomised design, factorial analysis of variance by SAS 9.2 software. Mean values were considered significantly different at $\mathrm{P}<0.05$. 


\section{Results and discussion}

\subsection{Evaluating the size and morphology of encapsulated particles}

In the present study, the sizes of spray dried particles of barberry fruit extracts were found to be $1-20 \mu \mathrm{m}$ by SEM (Fig. 1).
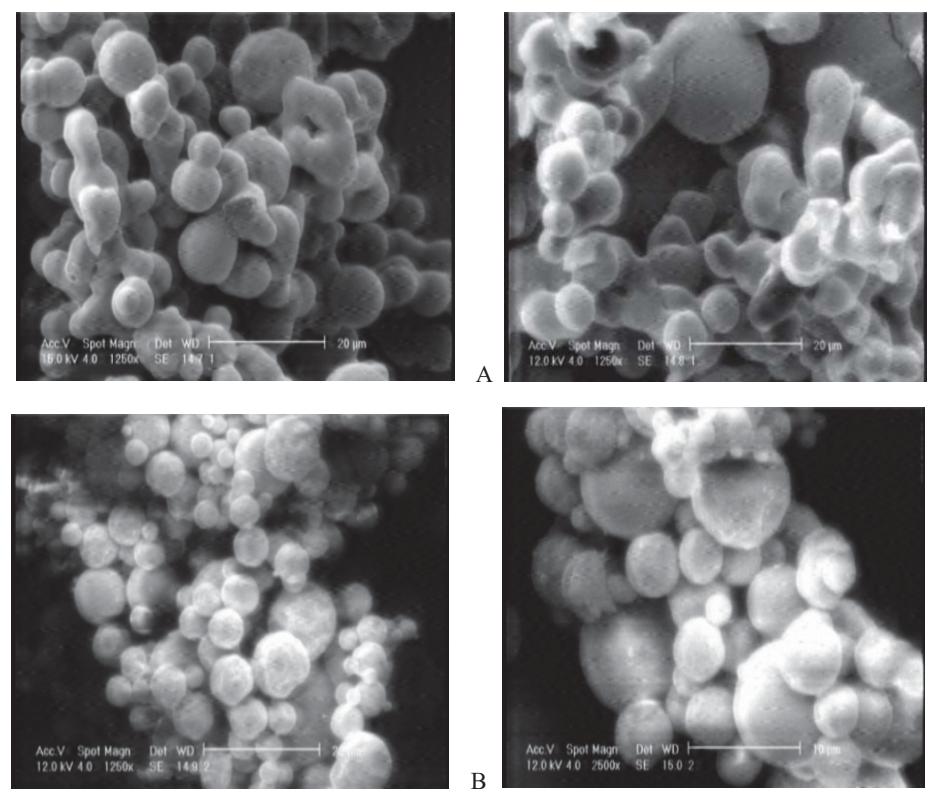

Fig. 1. SEM images of the spray dried microcapsules of B. vulgaris (A) and B. integrrima (B) extract in maltodextrin $(\mathrm{DE}=16.5-19.5)$

The size of spray dried particles of anthocyanin in maltodextrin measured using SEM was reported in the range of 2-50 $\mu \mathrm{m}$ measured (NAYAK \& RASTOGI, 2010). The particles size of acai juice spray dried in maltodextrin, arabic gum, and tapioca starch was in the range of $0.141 \mu \mathrm{m}$ (Tonon et al., 2010). The morphological evaluation in the present study showed that the thin layer liposomes had spherical shape. According to ABDALLA and Roozen (2001), the size of liposomes loaded with the extracts of sage and oregano, which were prepared similarly, was about 20-100 nm. In present research, the size of liposomes loaded with extracts of barberry fruit was larger than empty liposomes (Fig. 2). The particle size reported by DLS (Table 1) was hydrodynamic diameter of a particle + a layer of solvent surrounded (Fig. 3). Therefore, the reported diameter by DLS is larger than SEM reports as dry diameters of particles. According to Table 1, the amounts of z-average in loaded liposomes with barberry fruit extracts were smaller than empty liposomes. 
Table 1. The results of DLS analysis of liposomes at day 0

\begin{tabular}{lccccccccc}
\hline Sample & Solvent & $\begin{array}{c}\text { Refractive } \\
\text { index of } \\
\text { solvent }\end{array}$ & $\begin{array}{c}\text { Refractive } \\
\text { index of } \\
\text { particles }\end{array}$ & $\begin{array}{c}\text { Viscosity } \\
(\mathrm{cP})\end{array}$ & $\begin{array}{c}\text { Tempera- } \\
\text { ture } \\
\left({ }^{\circ} \mathrm{C}\right)\end{array}$ & $\begin{array}{c}\text { Time } \\
(\mathrm{s})\end{array}$ & $\begin{array}{c}\text { Z-Average } \\
(\mathrm{d} . n \mathrm{~m}) \\
\text { Mean } \pm \mathrm{SD}\end{array}$ & $\begin{array}{c}\text { Poly- } \\
\text { dispersity } \\
(\text { PdI })\end{array}$ & $\begin{array}{c}\text { Zeta } \\
\text { potential } \\
(\mathrm{mv}) \\
\text { Mean } \pm \mathrm{SD}\end{array}$ \\
\hline ELI & water & $1.33^{\mathrm{a}}$ & $1.33^{\mathrm{a}}$ & $0.8872^{\mathrm{a}}$ & 25.1 & 60 & $163.9 \pm 2.23^{\mathrm{a}}$ & $0.247^{\mathrm{b}}$ & $\begin{array}{c}-26.6 \pm \\
1.96^{\mathrm{a}}\end{array}$ \\
BVLI & water & $1.33^{\mathrm{a}}$ & $1.33^{\mathrm{a}}$ & $0.8872^{\mathrm{a}}$ & 25.1 & 60 & $135.2 \pm 2.04^{\mathrm{b}}$ & $0.252^{\mathrm{a}}$ & $\begin{array}{c}-21.6 \pm \\
0.98^{\mathrm{b}}\end{array}$ \\
BILI & water & $1.33^{\mathrm{a}}$ & $1.33^{\mathrm{a}}$ & $0.8872^{\mathrm{a}}$ & 24.9 & 60 & $113.4 \pm 1.83^{\mathrm{c}}$ & $0.242^{\mathrm{c}}$ & $\begin{array}{c}-28.4 \pm \\
2.26^{\mathrm{c}}\end{array}$ \\
\hline
\end{tabular}

ELI: Empty liposome; BVLI: liposome loaded with extract of $B$. vulgaris; BILI: liposome loaded with extract of B. integerrima. Different lowercase letters represent significant difference $(\mathrm{P}<0.01)$ in each column. Data for each treatment is mean \pm standard deviation (S.D.).

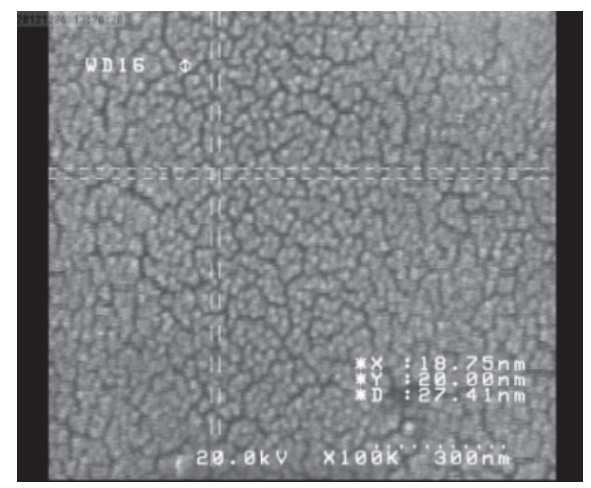

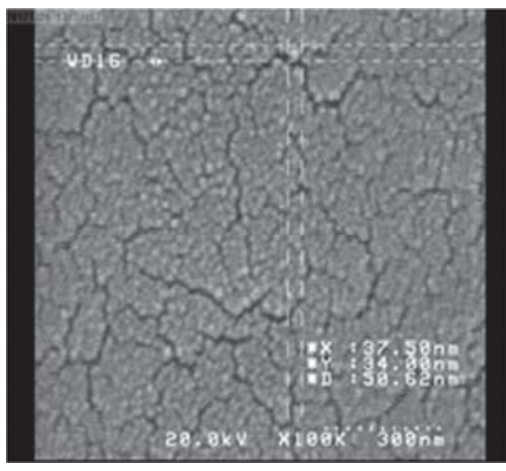

B

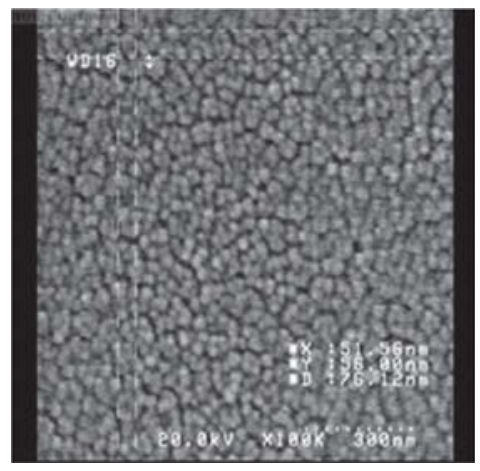

$\mathrm{C}$

Fig. 2. FE-SEM images of empty (A), liposomes loaded with the extract of $B$. vulgaris (B) and $B$. integerrima $(\mathrm{C})$ fruits

Polydispersity index that shows the homogeneity of the particle sizes in the suspension was about 0.250 ; smaller values represent more homogeneity. The optimum values are about 0.2-0.3 (FAN et al., 2007). In the present study, zeta potential values of liposomes were 
negative. FANG and co-workers (2007) reported surface negative charge of liposomes can be attributed to anionic portions such as phosphatidylserine and phosphatidylglycerol in phospholipids containing $80 \%$ phosphatidylcholine (inert). We used soy bean lecithin, which contained the highest amount of phosphatidylcholine $(65 \%)$, so surficial negative charge of liposomes can be attributed to the other phospholipids. Lu and co-workers (2011) found that the leakage of negative liposomes was smaller than positive ones, and generally, at the absolute potential of about $30 \mathrm{mV}$, the system is more stable. Results showed that the surface negative charge of liposomes loaded with the extract of $B$. integerrima was higher than that of the empty liposomes. According to Lu and co-workers (2011), it may be the result of the dissociation of polyphenols in the solution. GIBIs and co-workers (2012) found that by increasing $\mathrm{pH}$, the surface negative charge of liposomes and electrostatic repulsion will increase. In the present study, since phenolic and organic acids contents (anionic base) and $\mathrm{pH}$ of $B$. integerrima were higher, the surface negative charge of liposomes loaded with the extract of $B$. integerrima was higher than the two other types. Hydrophilic compounds are placed in the central empty hole of liposomes. The 5 phenols of olive oil did not penetrate into the phospholipid bilayer of liposomes. This may be related to their hydrophilic properties and non-surface structure (PAIVA-MARTINS et al., 2003). The increasing diameter of extract loaded liposomes is probably due to the phenolic compounds being situated not only in the central empty hole but also in the bilayer membrane and on the surface of liposomes, as well (GIBIS et al., 2012). Probably, in this study, the majority of the barberry fruit extracts were loaded in the central empty hole of liposomes, so it had no effect on the particle size. These three different types of liposomes were prepared at three different days, so some differences in particle size compared to each other is logical. SHISHIKURA and co-workers (2006) reported hydrogen bonds formation between hydroxyl groups of phenolics and polar heads of phospholipids. GIBIS and co-workers (2012) stated hydrophobic interactions between the fatty acid tails of polar lipids and hydrophobic moiety of phenolic compounds. Hydrogen bonds are observed in compounds containing hydrogen and small electronegative elements. In these compounds, the atoms of an electronegative element exert an intense attraction on the bond electrons. As a result, hydrogen possesses a considerable positive charge ${ }^{+} \sigma$ (MORTIMER, 1986). In the present study, probably hydrogen interactions between the hydroxyl groups of phenolic compounds in the extracts with polar compounds of phospholipids, polarpolar interactions between the polar parts of phenolics and other compounds in the extract such as vitamins and organic acids with the polar groups of phospholipids of liposomes, and even hydrophobic interactions between the hydrophobic moiety in the extract and tail of phospholipids could be formed. MorTimer (1986) believes that as a result of hydrogen bonding, hydrogen atom finds a high positive charge. In this study, the $B$. vulgaris extract contained less amounts of polyphenols, organic acids, water soluble vitamins and had lower $\mathrm{pH}$ value, and it showed a smaller negative charge in loaded liposomes and its negative zeta potential value decreased. However, in $B$. integerrima extract, all these parameters were higher compared with $B$. vulgaris, so the loaded liposomes had higher negative zeta potential. These interactions took place in an aqueous medium, which can cause an inclination towards the empty central hole of the loaded liposomes, and the size of loaded liposomes in water was a little smaller than control. The size of liposomes after 6 months at $-18^{\circ} \mathrm{C}$ showed a small increase, though the size of loaded liposomes was more stable than the empty ones. The size of empty liposomes was about $378.90 \mathrm{~nm}$, the loaded liposomes with B. vulgaris and $B$. integerrima extracts were 160.90 and $144.20 \mathrm{~nm}$ in size, respectively. 
A Size distribution by intensity

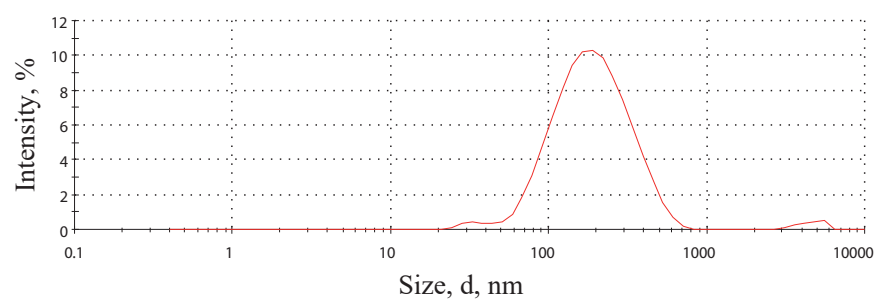

Record 5: EL 1

$\mathrm{B}$

Size distribution by intensity

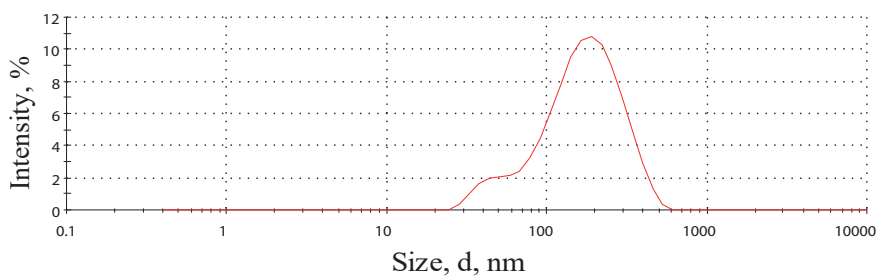

Record 4: BVL 1

C

Size distribution by intensity

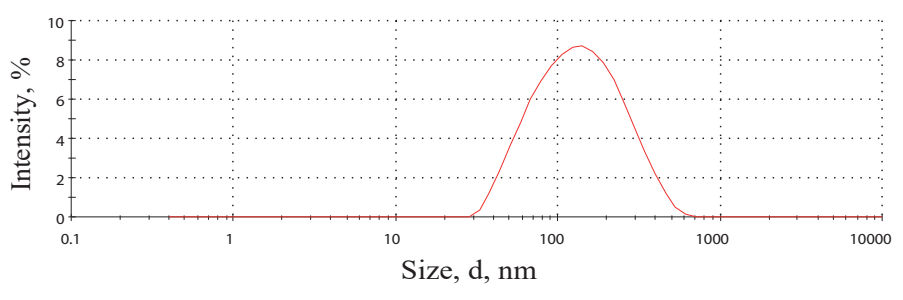

Fig. 3. The size distribution of particles on liposomal light scattering intense (Z-Average) by DLS of the empty (A) and loaded liposomes with B. vulgaris (B) B. integerrima (C) extracts

\subsection{Evaluation of the antioxidant ability of the encapsulated extract}

The results of the onset temperature of an oxidative destruction are shown in Table 2.

Thermal analysis methods such as DSC (under mild conditions and shorter time than Rancimat) are valuable to evaluate thermal and oxidative stability of volatile samples using the onset temperature of oxidation. An antioxidant can increase lag phase duration in chain oxidation reactions or block the chain reactions of a radical through interacting with peroxyl radicals (LiTWINIENKo et al., 1997). Figure 4 shows the DSC curves of $B$. integerrima and $B$. vulgaris extracts, their extracts capsulated in maltodextrin, extracts loaded and empty liposomes. As shown, there is an exothermic peak related to sample oxidation in the range of 180-360 ${ }^{\circ} \mathrm{C}$. According to Table 2, at 0, 45, and 90 days, the antioxidant activities of the encapsulated extracts were higher than of the controls, and they showed higher onset temperatures. The extracts loaded in liposomes had higher antioxidant properties. Also, the 
Table 2. The results of onset temperatures of oxidative destruction of different samples (DSC measurement)

\begin{tabular}{lccc}
\hline Sample & & Temperature & \\
& Day 0 & $45^{\text {th }}$ Day & $90^{\text {th }}$ Day \\
\hline EX-I & ${ }^{\mathrm{a}} 252.40^{\mathrm{C}}$ & ${ }^{\mathrm{b}} 249.36^{\mathrm{C}}$ & ${ }^{\mathrm{b}} 246.32^{\mathrm{D}}$ \\
EX-V & ${ }^{\mathrm{a}} 243.61^{\mathrm{D}}$ & ${ }^{\mathrm{b}} 241.89^{\mathrm{D}}$ & ${ }^{\mathrm{b}} 238.93^{\mathrm{E}}$ \\
MD-I & ${ }^{\mathrm{a}} 258.66^{\mathrm{B}}$ & ${ }^{\mathrm{b}} 254.40^{\mathrm{B}}$ & ${ }^{\mathrm{b}} 254.16^{\mathrm{B}}$ \\
MD-V & ${ }^{\mathrm{a}} 252.29^{\mathrm{C}}$ & ${ }^{\mathrm{a}} 251.14^{\mathrm{C}}$ & ${ }^{\mathrm{a}} 251.53^{\mathrm{C}}$ \\
LI-E & ${ }^{\mathrm{a}} 184.44^{\mathrm{E}}$ & ${ }^{\mathrm{a}} 182.71^{\mathrm{E}}$ & ${ }^{\mathrm{a}} 185.31^{\mathrm{F}}$ \\
LI-I & ${ }^{\mathrm{a}} 271.08^{\mathrm{A}}$ & ${ }^{\mathrm{a}} 270.64^{\mathrm{A}}$ & ${ }^{\mathrm{a}} 270.28^{\mathrm{A}}$ \\
LI-V & ${ }^{\mathrm{a}} 270.79^{\mathrm{A}}$ & ${ }^{\mathrm{a}} 269.11^{\mathrm{A}}$ & ${ }^{\mathrm{a}} 269.97^{\mathrm{A}}$ \\
\hline
\end{tabular}

EX-I: Extract of B. integerrima, EX-V: extract of B. vulgaris; MD-I: spray dried extract of B. integerrima in maltodextrin; MD-V: spray dried extract of B. vulgaris; LI-E: empty liposome; LI-I: liposome loaded with the extract of $B$. integerrima; LI-V: liposome loaded with the extract of $B$. vulgaris. Data are shown as the average of three measurements. Capital letters show significant difference in a column and lowercase letters represent significant difference in rows $(\mathrm{P}<0.05)$

extract of $B$. integerrima showed higher antioxidant activity than that of B. vulgaris, because of its higher phenolic compounds content (Fig. 4). The onset temperatures of empty liposomes, extract of Myrtus communis, and liposomes loaded with this extract were 218, 237, and 272 ${ }^{\circ} \mathrm{C}$, respectively. At equal heating rate, the onset temperature of oxidation was significantly higher in capsulated samples, although the antioxidant activity of the empty liposomes was meaningfully lower than the loaded ones. This means that encapsulated extract compounds in the aqueous moiety of liposomes and lipophilic bonds to lipid bilayers will stabilise the liposomes' membranes (GoRTzI et al., 2007). The results of Thymus spp. extract encapsulation for the preservation of antioxidants (GoRTZI et al., 2006) agree with the results of this study. PAIVA-MarTins and co-workers (2003) found long lag phase for loaded liposomes with phenols of olive oil, showing that phenolic compounds can effectively delay phospholipids peroxidation in liposomes compared with empty liposomes. Maltodextrin has high solubility, so when the feed passes the spray drier hollow particles are produced with crusts containing both agents of carrier and fruit juice, which is considered as an encapsulated juice (TONON et al., 2010). Maltodextrin can protect phenolic and anthocyanin contents of violet sweet potato during flour processing. Maltodextrin encapsulated flours had higher phenolic content and antioxidant capacity than common flours. There was no significant difference between the anthocyanin contents of encapsulated and non-encapsulated flours (AHMED et al., 2010). Maltodextrin provided higher anthocyanin and polyphenol contents, and consequently, higher antioxidant activity compared with inulin at the end of the spray drying process. Nonetheless, powders with inulin were more stable at temperatures 8 and $25^{\circ} \mathrm{C}$ for 12 months (BSKOWSKa-BARCZAK \& KolODZIEJCZYK, 2011). During 6 months of storage at $5{ }^{\circ} \mathrm{C}$ of bayberry powder spray dried in maltodextrin, total phenolic and anthocyanin contents decreased by $6-8 \%$ and $7-27 \%$, respectively, which means the decline of scavenging capacity $\left(\mathrm{SC}_{50}\right)$ and antioxidant capacity during storage (FANG \& BHANDARI, 2011). The recovery of polyphenols from cactus pear extract spray dried in maltodextrin was higher than control. It can be attributed to the hydrolysis of linked polyphenols during sample preparation or drying process (SAENZ et al., 2009). Maltodextrin proved significantly better than soy 
protein isolates in preventing anthocyanin decomposition in fruit juice and extract. Decomposition of polyphenols and anthocyanin in fresh juice was faster than in the microencapsulated juice (ROBERT et al., 2010). In the present study, maltodextrin DE 19.5 was used to encapsulate the extracts of $B$. vulgaris and B. integerrima fruits. DSC results did not show significant difference between the onset temperatures of oxidation reaction during the 90 days of storage at $4{ }^{\circ} \mathrm{C}$. This means that there was no significant reduction in the amounts of antioxidant compounds (phenolic compounds and anthocyanins).

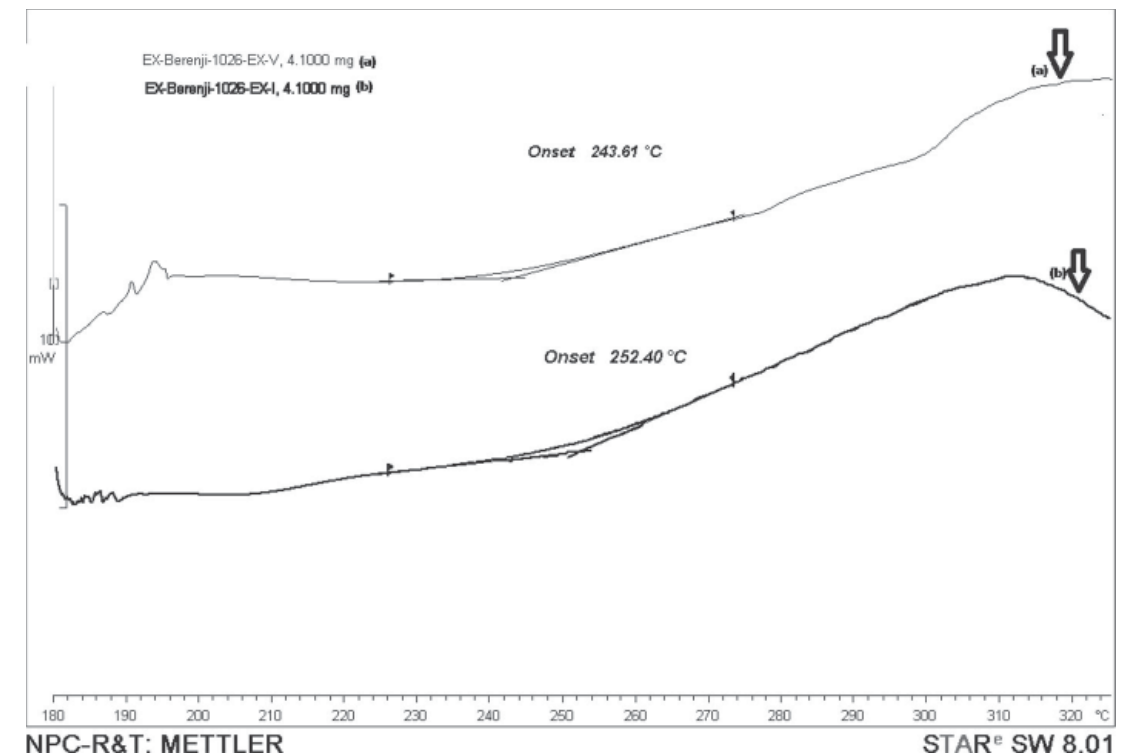

Fig. 4. Results of DSC measurements

Fig. 4-1. DSC curves of B. vulgaris (b) and B. integerrima (a)

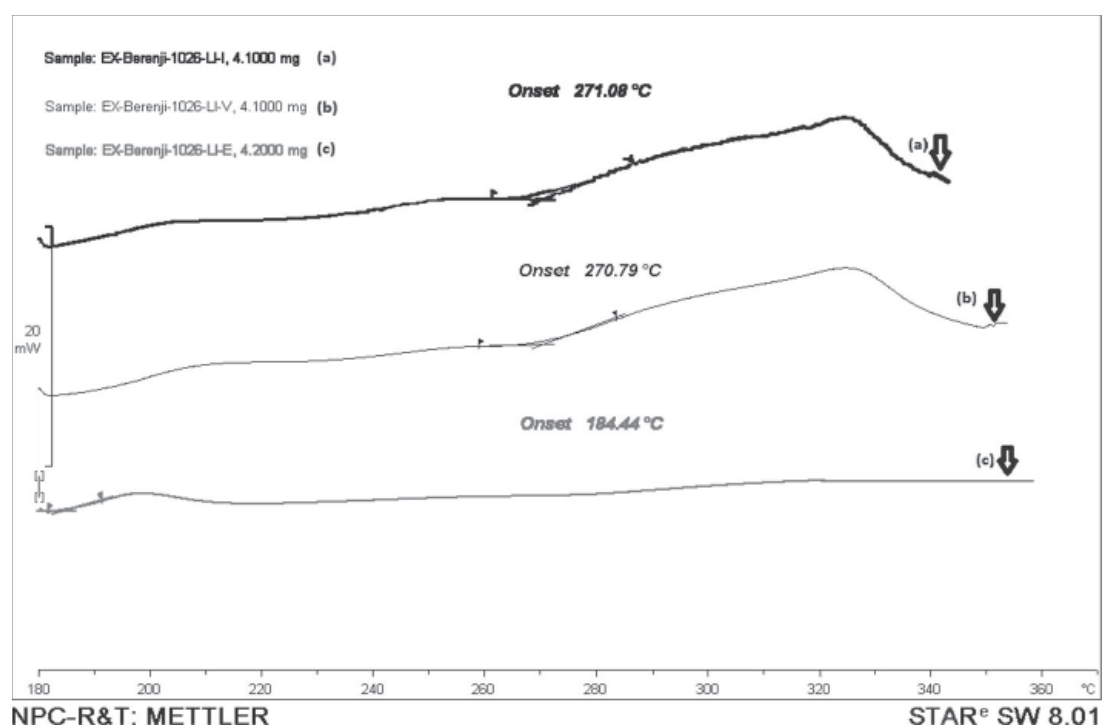

Fig. 4-2. DSC curves of empty (c) and loaded liposomes with B. vulgaris (b) and B. integerrima (a) 


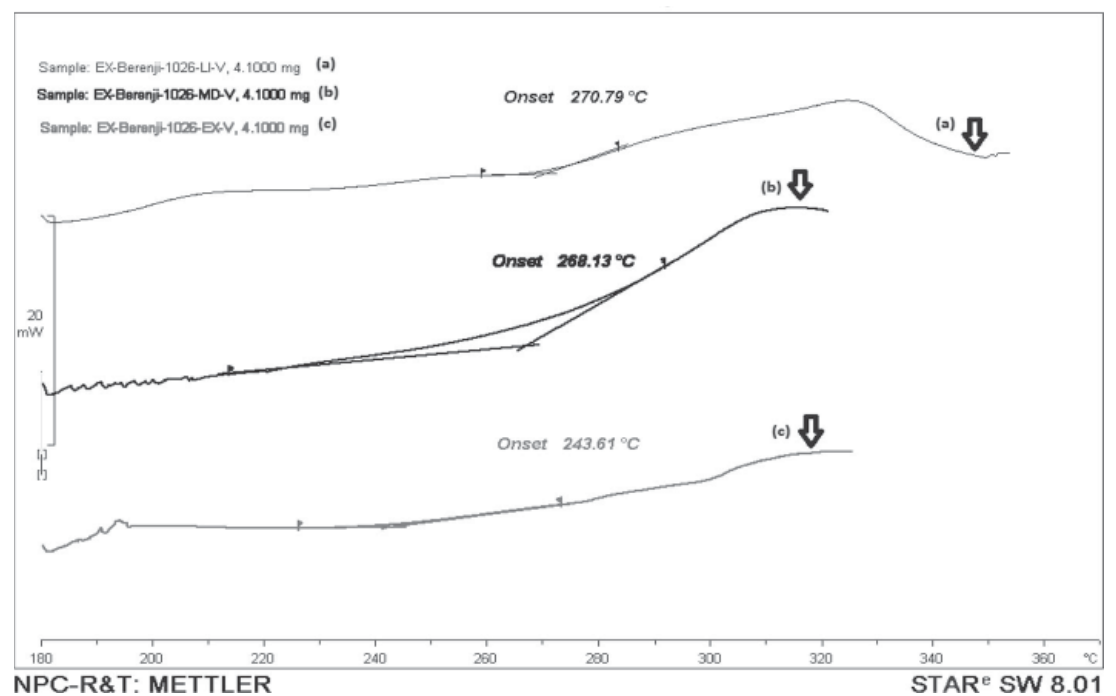

Fig. 4-3. DSC curves of control sample (c), spray dried powders (b) and B. vulgaris loaded liposomes (a)

\section{Conclusions}

The extracts of Berberis integerrima and $B$. vulgaris (in water, absence of light, at $\mathrm{pH}=3$ and $25^{\circ} \mathrm{C}$ ) were spray dried encapsulated with maltodextrin (particle size of 1-20 $\mu \mathrm{m}$ ) and liposome entrapment (dry particle size of 40-80 $\mathrm{nm}$ and negative surface charge). According to the results at time 0 , the antioxidant activity of the encapsulated extracts was higher than of the controls, therefore, the initiation temperature of oxidation increased. After 45 and 90 days, the encapsulated extracts kept their antioxidant properties better and showed higher oxidation initiation temperatures. Evaluation by scanning colorimetry (DSC) at 0 (control), 45, and 90 days showed higher antioxidant activity in the encapsulated extract with liposomes than with maltodextrin or the control.

This study was supported by the Faculty of Agriculture, Tarbiat Modares University, Iran.

\section{References}

Abdalla, A.E. \& Roozen, J.P. (2001): The effects of stabilized extracts of sage and oregano on the oxidation of salad dressings. Eur. Food Res. Technol., 212, 551-560.

Ahmed, M., Akter, M.S., Lee, J.C. \& Eun, J.B. (2010): Encapsulation by spray drying of bioactive components, physicochemical and morphological properties from purple sweet potato. LWT-Food Sci. Technol., 43, 1307-1312.

Berenji Ardestani, S., Sahari, M.A. \& Barzegar, M. (2016): Effect of extraction and processing conditions on anthocyanins of barberry. J. Food Process. Pres., 40, 1407-1420.

Bskowska-Barczak, A.M. \& KolodziejczyK, P.P. (2011): Black currant polyphenols: Their storage stability and microencapsulation. Ind. Crop Prod., 34, 1301-1309. 
FAN, M., XU, S.H., XIA, S.H. \& ZHANG, X. (2007): Effects of different preparation methods on physicochemical properties of Salidroside liposomes. J. Agr. Food Chem., 55, 3089-3095.

FanG, J.Y., HunG, C.F., LiaO, M.H. \& ChiEN, C.C. (2007): A study of the formulation design of acoustically active lipospheres as carriers for drug delivery. Eur. J. Pharm. Biopharm., 67, 67-75.

FANG, Z. \& BHANDARI, B. (2010): Encapsulation of polyphenols - a review. Trends Food Sci. Tech., 21(10), 510-523.

FANG, Z. \& BHANDARI, B. (2011): Effect of spray drying on the stability of bayberry polyphenols. Food Chem., 129, $1139-1147$.

Gibis, M., Vogt, E. \& Weiss, J. (2012): Encapsulation of polyphenolic grape seed extract in polymer-coated liposomes. Food Funct., 3, 246-254.

Gortzi, O., Lalas, S., Chinou, I. \& Tsakins, J. (2006): Reevaluation of antimicrobial and antioxidant activity of Thymus spp. extracts before and after encapsulation in liposomes. J. Food Protect., 69, 2998-3005.

Gortzi, O., Lalas, S., Chinou, I. \& Tsakins, J. (2007): Reevaluation of bioactivity and antioxidant activity of Myrtus communis extract before and after encapsulation in liposomes. Eur. Food Res. Technol., 226, 583-590.

LitwinienKo, G., KasprZyCKa-GutTMAn, T. \& StudZinski, M. (1997): Effects on selected phenol derivatives on the autoxidation of linolenic acid investigated by DSC non-isothermal methods. Thermochim. Acta, 307, 97 106.

LU, Q., LI, D.C. \& JiAnG, J.G. (2011): Preparation of a tea polyphenol nano liposomes system and its physicochemical properties. J. Agr. Food Chem., 59, 13004-13011.

MoHAN, C. (2003): A guide for the preparation and use of buffers in biological systems. EMD Biosciences, Inc., An affiliate of Merck KGaA, Darmstadt, Germany. p. 37.

Mortazavi, A., Motamedzadegan, A. \& Ziaolhagh, H.R. (2008): Non-thermal preservation of food. Ferdowsi university of Mashhad Publishing, Mashhad, Iran (In Farsi), $1^{\text {st }}$ ed., pp. 219-291.

Mortimer, C.E. (1986): Chemistry. $6^{\text {th }}$ ed., Wadsworth Publishing Company, Belmont, CA. p. 902.

Motalleb, G., Hanachi, P., Kua, S.H., Fauziah, O. \& Asmah, R. (2005): Evaluation of phenolic content and total antioxidant activity in Berberis vulgaris fruit extract. J. Biol. Sci., 5, 648-653.

NAYAK, C.A. \& RASTOGI, N.K. (2010): Effect of selected additives on microencapsulation of anthocyanin by spray drying. Dry. Technol., 28, 1396-1404.

Paiva-Martins, F., Gordon, M.H. \& Gameiro, P. (2003): Activity and location of olive oil phenolic antioxidants in liposomes. Chem. Phys. Lipids., 124, 23-36.

Robert, P., Gorena, T., Romero, N., Sepulveda, E., Chavez, J. \& Saenz, C. (2010): Encapsulation of polyphenols and anthocyanins from pomegranate (Punica granatum) by spray drying. Int. J. Food Sci. Tech., 45, 13861394.

RoberTs, W.G. \& Gordon, M.H. (2003): Determination of the total antioxidant activity of fruits and vegetables by a liposome assay. J. Agr. Food Chem., 51, 1486-1493.

Saenz, C., Tapia, S., Chavez, J. \& Robert, P. (2009): Microencapsulation by spray drying of bioactive compounds from cactus pear (Opuntia ficus-indica). Food Chem., 114, 616-622.

Shishikura, Y., KHokHar, S. \& MurraY, B.S. (2006): Effects of tea polyphenols of olive oil in a small intestine model system. J. Agr. Food Chem., 54, 1906-1913.

Tonon, R.V., Brabet, C. \& Hubinger, M.D. (2010): Anthocyanin stability and antioxidant activity of spray-dried acai (Euterpe oleracea Mart.) juice produced with different carrier agents. Food Res. Int., 43, 907-914. 